Review

\title{
Tumor Necrosis Factor-a Induced Protein 8: Pathophysiology, Clinical Significance, and Regulatory Mechanism
}

\author{
Lei Zhang1,2, Ran Liu³, Ying-yi Luan¹, Yong-ming Yao ${ }^{1 凶}$ \\ 1. Trauma Research Center, First Hospital Affiliated to the Chinese PLA General Hospital, Beijing 100048, People's Republic of China. \\ 2. Emergency Department, The General Hospital of the Chinese PLA Rocket Force, Beijing 100088, People's Republic of China. \\ 3. Department of Endocrinology, 307th Hospital of the Chinese PLA, Beijing 100071, People's Republic of China. \\ $\triangle$ Corresponding author: Yong-ming Yao; E-mail: c_ff@sina.com; Tel: (+86)1066867394; Fax: (+86)1068989158. Department of Microbiology and Immunology, \\ Trauma Research Center, First Hospital Affiliated to the Chinese PLA General Hospital, Fucheng Road 51, Haidian District, Beijing 100048, People's Republic of \\ China. \\ (c) Ivyspring International Publisher. This is an open access article distributed under the terms of the Creative Commons Attribution (CC BY-NC) license \\ (https://creativecommons.org/licenses/by-nc/4.0/). See http://ivyspring.com/terms for full terms and conditions.
}

Received: 2017.10.10; Accepted: 2018.02.26; Published: 2018.03.10

\begin{abstract}
Tumor necrosis factor- $\alpha$-induced protein-8 (TNFAIP8) is the earliest discovered component of TNFAIP8 family [tumor necrosis factor- $\alpha$-induced protein-8 like (TIPE) family]. TNFAIP8 contains a putative death effector domain (DED) homologous to DED II in FLIP (Fas-associated death domain-like interleukin-1 $\beta$-converting enzyme-inhibitory protein), which may affect cell survival/death process. Recently, it has been demonstrated that TNFAIP8 could inhibit apoptosis and autophagy in various types of cells. Moreover, TNFAIP8 level fluctuated evidently in patients with inflammatory, malignant, and autoimmune diseases, indicating that it might be an anti-apoptotic and oncogenetic protein. Herein we will review the discovery, gene/protein structure, pathophysiological functions, and clinical significance of TNFAIP8 together with its potential regulatory mechanism.
\end{abstract}

Key words: Tumor Necrosis Factor-a Induced Protein-8; Inflammation; Tumor; Apoptosis; Autophagy; Immune Response

\section{Introduction}

Tumor necrosis factor alpha induced protein- 8 (TNFAIP8) family is a recently described protein family, which plays important roles in immune homeostasis, inflammatory responses, tumor genesis and development as well as cell signal transduction. Many articles regarding TNFAIP8 family were published in the last two decades, which enable us to know the update advances in functions and mechanisms of various member proteins. In this review, we focus on TNFAIP8, the first discovered protein in this family, and elaborate its structure, function, biological and pathophysiological effects, regulatory mechanisms and clinical significance.

\section{TNFAIP8 family}

Discovered in late 20th century, the TNFAIP8 protein family is consisted of 4 different proteins, in terms of TNFAIP8 (TIPE), TNFAIP8 like 1 (TIPE1), TNFAIP8 like 2 (TIPE2), and TNFAIP8 like 3 (TIPE3). These proteins are structurally similar with each other and share approximately $54 \%$ identical sequences [1]. Some researchers believe that TNFAIP8 family proteins have rare similarities with other type of proteins except for a common death effector domain (DED) $[2,3]$. Whereas, a crystal structure analysis by Zhang et al. showed that the putative DED domain contained in TIPE2 was not actually a DED, but a mirror image of DED in topological structure more accurately, which had six a-helices within its amino acid chain and formed a large cylindrical cavity. This centrally located, hydrophobic cavity may act as a binding site of cofactors and might be associated with 
immune homeostasis maintenance. Considering the high sequence conservation between TIPE2 and TIPE1, TIPE3 or TNFAIP8, this kind of structure might be a common protein domain shared by all TFNAIP8 family members [4].

It has been indicated that the member proteins behave differently in functions (Table 1) [2-14]. TNFAIP8 can regulate cell apoptosis and is related to neoplasia, tumor development and prognosis. TIPE1 is considered as a pro-apoptosis factor that can enhance cell apoptotic effects. TIPE2 acts as a negative regulator of immune system and inflammatory response, and also has the ability of tumor inhibition. As a transporter of lipid second messengers, TIPE3 is over-expressed in many kinds of tumor tissues, which shows a potential relationship with tumorigenesis. Among these members, TIPE2 is most profoundly elucidated after its discovery in 2008. Nevertheless, there is limited literature available concerning TIPE1 and TIPE3, which were identified respectively in 2010 and 2011 (Figure 1).

\section{TNFAIP8 protein: gene, protein structure and function}

Patel et al. identified a new transcript in 1997 through comparison of primary and metastatic cell lines from human head and neck squamous cell carcinoma, thus TNFAIP8 was originally called squamous cell carcinoma-subclone2 (SCC-S2) [15]. It has also been named as NDED, Oxi-a, GG2-1, MDC3.13 in the early few years. TNFAIP8 gene is highly conservative among various species [16, 17], and human TNFAIP8 gene is located at 5 chromosome q23 region [18, 19]. The open reading frame of TNFAIP8 gene is a specific sequence in its amino-terminal which is extremely homologous to DED II domain in Fas-associated death domain-like interleukin-1 $\beta$-converting enzyme-inhibitory protein (FLIP) [20]. There is a growing body of evidence showing that TNFAIP8 is the key regulating gene in murine thymocyte apoptosis induced by glucocorticoid [21]. Likely, TNFAIP8 gene can modulate the immune function of $\mathrm{CD}^{+} \mathrm{T}$ cells both in mice and humans $[22,23]$. Recent transcriptome and proteome studies showed that TNFAIP8 knockout resulted in up-regulation of some anti-proliferative and apoptotic genes in different human cancer cell lines, meanwhile, many oncogenes were markedly down-regulated [24]. Differential methylation of TNFAIP8 gene was reported to be associated with the preterm birth rate in the black population [25]. TNFAIP8 mRNA was expressed in various normal tissues and over-expressed in malignant cells. Furthermore, expression of TNFAIP8 mRNA could be activated by tumor necrosis factor (TNF)- $a$, and up-regulation of TNFAIP8 mRNA inhibited cell apoptosis stimulated by TNF-a [20].

Table 1. Function of TNFAIP8 family member proteins.

\begin{tabular}{llll}
\hline TNFAIP8 & TIPE1 & TIPE2 & TIPE3 \\
\hline Apoptosis & Pro-apoptotic & Negative regulator of & Transporter of \\
regulation; & protein. & immunity and & lipid second \\
Tumor genesis, & & inflammation; & messengers; \\
development, & & Maintaining homeostasis; & Tumorigenesis. \\
metastasis, and & & Inhibition of & \\
prognosis. & & tumorigenesis. & \\
\hline
\end{tabular}
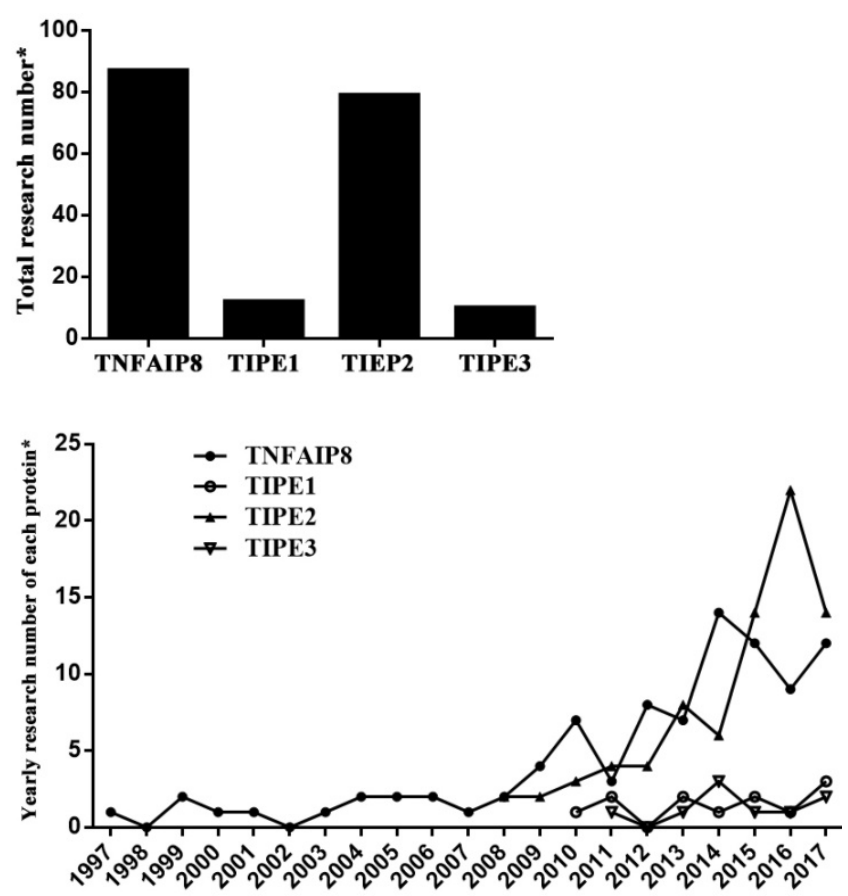

Figure 1. Current research situation of TNFAIP8 family. *: PubMed searching in August 2017.

TNFAIP8, a $21 \mathrm{kD}$ cytoplasmic protein, is reported to be expressed in both cytoplasm and cell nucleus in human prostate cancer cells [26]. Most human normal tissues express TNFAIP8 which is highly expressed in immunity-related tissues such as lymphatic system, spleen, thymus gland, thyroid, bone marrow, and placenta, while solid organs including ovary, kidney, heart, brain, testicle, and skeletal muscle show relatively lower TNFAIP8 expression. Carcinoma tissues can usually over-express TNFAIP8. In addition, it was noticed that TNFAIP8 was enriched in kidney, brain and spleen in rats $[2,27]$.

It has been indicated that TNFAIP8 appears to be involved in the process of TNF- $\alpha$ induced cell apoptosis. TNF-a can bind to tumor necrosis factor receptor 1 (TNFR1), which then enhance the TNFAIP8 expression through the activation of nuclear factor (NF)-кB. The up-regulated expression and activity of 
TNFAIP8 significantly inhibit the caspase cascades, which result in a decrease of cell apoptosis (Figure 2) [28]. The orphan nuclear receptor chicken ovalbumin upstream promoter transcription factor I (COUPI-TFI) acts with several transcriptional regulators, combines to the promoter of TNFAIP8 gene and inhibits protein synthesis. TNF-a can reduce the expression of COUPI-TFI in both mRNA and protein level, which boosts the effects of TNFAIP8 (Figure 2) [29]. Laliberté B et al., found that Gai3 subunit of $G$ protein coupled receptor could prevent cell death and promote the oncogenic transformation of normal cells by direct Gai3-TNFAIP8 coupling [30].

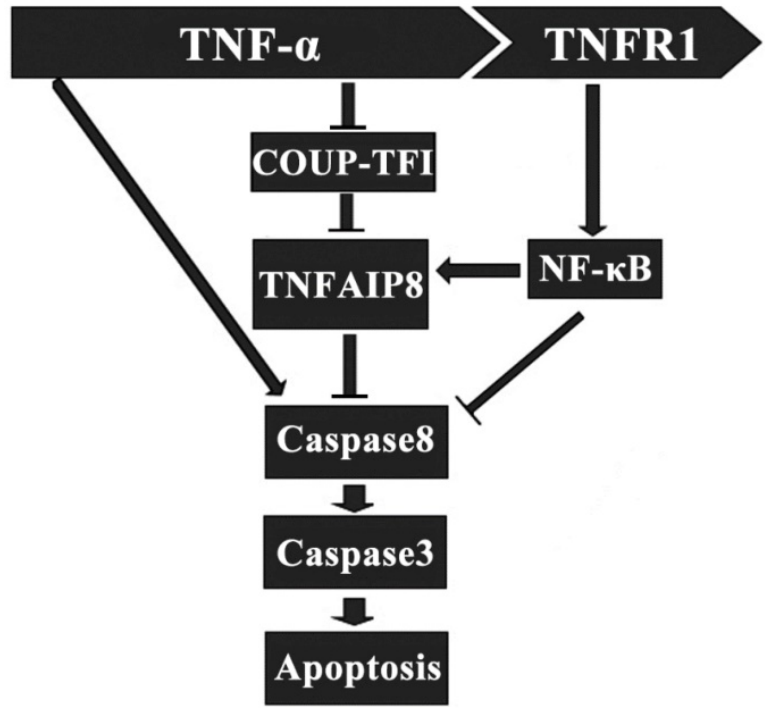

Figure 2. Regulatory effect of TNFAIP8 in cell apoptosis. TNFR1: tumor necrosis factor receptor 1; COUP-TFI: chicken ovalbumin upstream promoter transcription factor I.

Autophagy is another pathway through which TNFAIP8 influences cell survival/death. The Drosophila TIPE family member may be related to c-jun amino-terminal kinase (JNK) signaling, cytoskeletal remodeling and cell autophagy [31]. A dopaminergic neuron study revealed that TNFAIP8 evidently reduced the oxidative stress injury in murine neurons. TNFAIP8 could stimulate mammalian target of rapamycin (mTOR), suppress the development and aggregation of autophagic vacuoles and maintain cell to survive, yet this effect could be obviously reversed by rapamycin, the mTOR inhibitor and autophagy inducer. As an autophagy inhibitor, 3-methyladenine (3-MA) could markedly inhibit the autophagic response in dopaminergic neuron (Figure 3) [32]. A recently released article of the same research team obtained coincident results which highlighted the anti-autophagy effect of TNFAIP8-PE (phosphatidylethanolamine) complex [33].

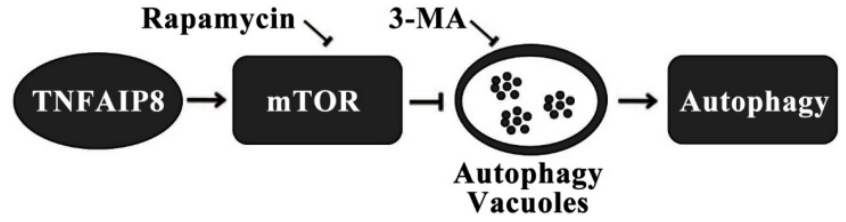

Figure 3. Mechanism of autophagy inhibition by TNFAIP8 in dopaminergic neuron. 3-MA: 3-Methyladenine; mTOR: Mammalian target of rapamycin.

\section{TNFAIP8 and malignant diseases}

\section{Respiratory system}

A non-small-cell lung cancer (NSCLC) clinical trial showed that more than $70 \%$ cancer tissue samples over-expressed TNFAIP8 mRNA compared to normal tissue, which was correlated to patients' lymph node metastasis, TNM staging, Ki-67 expression in cancer tissue, and poor prognosis [34]. Similarly, another NSCLC research found that TNFAIP8 mRNA level was lower in tumor infiltrated $\mathrm{CD}^{+}$and $\mathrm{CD}^{+} \mathrm{T}$ cells, especially in $\mathrm{CD}^{+} \mathrm{T}$ cells infiltrated by advanced stage NSCLC, indicating that TNFAIP8 might affect disease process through its interference with T cell function [35].

\section{Digestive system}

In patients with gastric cancer, enhanced mRNA and protein level of TNFAIP8 expression in tumor tissue were positively associated with lymph node metastasis and TNM staging, but negatively with prognosis [18, 36-38]. It was also reported that TNFAIP8 expression had relationship with serum CA72-4 concentration in patients, which was a crucial biomarker of digestive system carcinoma. Thus, down-regulation of TNFAIP8 might be a promising approach for treating human gastric cancer [36]. In mouse model, TNFAIP8-silencing could impair the cancer formation of BGC823 cells in vivo and enhance the anti-tumor effect of anti-death receptor 5 monoclonal antibody (anti-DR5ScFv, an inducer of cell apoptosis) [37]. As we known, microRNAs can regulate protein translation in post-transcriptional level, once dysfunctional, cancers may be developed. From a report by Gao et al., TNFAIP8 was found to be a direct target of miR-9 in human gastric cancer and over-expression of miR-9 significantly downregulated the expression of TNFAIP8, thereby inhibiting gastric cancer cell proliferation [39].

In human liver cells, the Hippo signaling pathway promotes intercellular contact inhibition, diminishes cell proliferation and induces apoptosis, which is of great significance in progress of hepatocellular carcinoma. TNFAIP8 could inhibit the phosphorylation of large tumor suppressor 1 (LATS1) and Yes-associated protein (YAP), reduce their 
translocation into nucleus and down-regulate the expression of downstream genes, which might accelerate the invasion and metastasis of hepatocellular carcinoma. Regression analysis revealed that TNAIP8 was an independent prognostic factor of hepatocellular carcinoma [40]. With 56 pancreatic cancer patients included, a clinical trial conducted in 2012 showed that poor differentiation cancer tissues expressed higher level of TNFAIP8 which positively correlated with tumor staging, lymph node metastasis and tissue expression of epidermal growth factor receptor (EGFR) [41].

Current treatment for colorectal cancer is unsatisfied in case the patients present with diseases in advanced stage. A Chinese study demonstrated that over-expression of TNFAIP8 was commonly seen in colon cancer cells, which could modulate the activity of cyclin D1 and phospho-Rb, motivate cell transition from G1 phase to $S$ phase. These results make TNFAIP8 a candidate therapeutic target in colon cancer [42]. In esophageal squamous cell carcinoma, TNFAIP8 expression was correlated to tumor's TNM stage, metastatic ability, prognostic situations as well as the lymphoid system relapse after Ivor Lewis esophagectomy [43, 44].

\section{Endocrine and hematologic system}

It was reported that TNFAIP8 level in human papillary thyroid carcinoma tissue was significantly elevated compared to that in adjacent noncancerous thyroid tissues, more intriguingly, TNFAIP8 levels in peripheral and tumor infiltrating $\mathrm{CD}^{+} / \mathrm{CD}^{+} \mathrm{T}$ cells were increased, contributing to the immune pathogenesis of thyroid carcinoma [45]. The polymorphism of TNFAIP8 gene may affect the Non-Hodgkin's lymphoma (NHL) susceptibility in Chinese population. A 514 NHL patients case-control report showed that TNFAIP8 rs1045241 CC genotype populations were more susceptible to both T and B cell NHL than those of CT/TT genotype [19, 46]. Meanwhile, TNFAIP8 genotype was found to be correlated to other types of hematologic carcinoma including diffuse large B-cell lymphoma, acute myeloid leukemia, and multiple myeloma [47-49].

\section{Urinary system}

"Promoter Array" analysis of human prostate cells [50, 51] screened out eight genes including TNFAIP8, which were differently methylated in their promoter regions between prostate epithelial and cancer cell lines. Differentially methylation and regulation of TNFAIP8 gene predict its potential role in the pathogenesis of prostate cancer. For example, androgen could induce prostate cancer cells to over-express TNFAIP8, and TNFAIP8 expression in both cytoplasm and nucleus was correlated to the severity of prostate cancer. Furthermore, nuclear TNFAIP8 level was an independent predictive factor of cancer recurrence. However, knockdown of TNFAIP8 was found to be associated with increased expression of several anti-proliferative and apoptotic genes and decreased levels of multiple oncogenes as well as onco-proteins. Transcriptome study identified that an intron of human TNFAIP8 gene was useful in the diagnosis/prognosis of prostate cancer [52]. Also, TNFAIP8 gene affected the function of androgen receptor in LNCaP cells, a human prostate cancer cell line [53]. TNFAIP8-karyopherin a2 immune complex in LNCaP cells facilitates the transportation of TNFAIP8 into nucleus, which could interact with integrins and matrix metalloproteinases (MMPs), and accelerate the progression of prostate cancers [26].

\section{Genital system}

In endometrial cancer patients, TNFAIP8 expression was evident to be correlated to patients' international federation of gynecology and obstetrics (FIGO) stage, cell differentiation, depth of myometrial invasion, lympho-vascular space invasion, lymph node metastasis, cancer relapse, and prognosis. Likely, TNFAIP8 over-expression had strong correlations with Ki-67 and MMP-9 levels in tumor samples [54]. In cervical cancer, TNFAIP8-rs11064 polymorphism interfered the bond intensity of miR-22-TNFAIP8-mRNA combination. Patients with GG genotype over-expressed TNFAIP8 and showed higher risks for cervical cancer [55]. In epithelial ovarian cancer patients, TNFAIP8 over-expression was associated with tumor metastasis, platinum resistance, and prognosis [56, 57].

\section{Musculoskeletal system}

The tumor-suppressive miR-99a is repressed in human osteosarcoma (OS) cells, and restoring its function can inhibit cell proliferation and induce apoptosis. Luciferase assay showed that miR-99a bound with TNFAIP8 directly and specifically, and up-regulation of miR-99a drastically depressed the TNFAIP8 mRNA and protein level in OS cells. These findings suggested that miR-99a played a significant tumor-suppressing role via its direct target TNFAIP8 in OS and might be a promising diagnostic and therapeutic target for OS patients [58].

\section{Breast cancer}

With regard to breast cancer, a team from Georgetown University Medical Center performed a serial study in 2004 and 2005. The results showed that TNFAIP8 over-expression increased the cell growth rate and tumorigenicity, up-regulated collagen I level and enhanced cancer migration in MDA-MB 435 cells 
transfected with TNFAIP8 cDNA [59]. Overexpression of TNFAIP8 significantly augmented the vascular endothelial growth factor receptor 2 (VEGFR-2), MMP-1, and MMP-9 levels in the same cell line, thereby promoting the cancer cells to metastasize [60]. These results coincide with the conclusion of a recent clinical trial which showed that invasive ductal breast cancer (IDC) patients with higher level of TNFAIP8 developed tumors of higher-grade malignancy and possessed shorter overall and disease-free survival time [61].

\section{Oncogenes and anti-oncogenes}

p53, an anti-oncogene which has the highest relativity with human oncogenesis, often loses its tumor suppressive functions when mutations occur. A rare p53 mutation K120R prompts its encoded protein to bind and active TNFAIP8 gene, which then helps human lung and colorectal tumor cells to survive. Activated TNFAIP8 is also critical for the tumor cells with K120R mutation to evade apoptosis [62]. It was found that a transcriptional variant of TNFAIP8 gene, TNFAIP8 v2, was over-expressed in various types of tumor cell lines, including U2OS, A549, THP-1, HCT-116, Raji, and H1299. Silencing the expression of TNFAIP8 v2 could inhibit the DNA synthesis, enhance the cell cycle arrest induced by p53, and exacerbate the DNA damage. Thus, TNFAIP8 v2 may act as a regulatory target of p53 and impair the anti-tumor effects of normal p53 protein. In cancer cells treated with doxorubicin, p53 protein combined with the enhancer of TNFAIP8 gene, up-regulated the expression of TNFAIP8 v2, and repressed cell apoptosis. This could be one of the causes of doxorubicin resistance [63].

\section{Oncolytic virotherapy of malignant diseases}

Oncolytic virotherapy is a novel strategy for treatment of cancers. Canine distemper virus (CDV) has been proved to be an oncolytic virus and can induce apoptosis in various kinds of human and canine-derived cells. It was noted that CDV remarkably enhanced the apoptosis of Hela cells through up-regulation of caspase-3 expression [64]. Human breast tumor cell line transfected with CDV showed a lower proliferation rate, and more than $45 \%$ transfected cells underwent apoptosis or necrosis. In addition, mitochondrial membrane depolarization was positively correlated with virus titres, and CDV $\mathrm{M}$ gene expression with TNFAIP8 as well. These results suggest TNFAIP8 may contribute to the oncolytic effects of CDV [65].

Over-expression TNFAIP8 is frequently observed in malignant cells, which is strongly linked to their excessive proliferation, reduced apoptosis, enhanced invasion and metastasis. Therefore, TNFAIP8 might serve as a predominant pro-tumor factor. Possible modulators and molecular targets of TNFAIP8 in malignant diseases are listed in table 2 .

Table 2. Potential modulators and molecular targets of TNFAIP8 in malignant diseases.

\begin{tabular}{|c|c|c|c|}
\hline Molecule/Gene & Belongs to & Correlations with TNFAIP8 and Possible Effects & References \\
\hline Ki-67 & Nuclear protein & $\begin{array}{l}\text { Positively correlating with TNFAIP8, increasing the transcription of ribosome } \\
\text { RNA and cell proliferation }\end{array}$ & {$[34,54]$} \\
\hline MMP-1, MMP-9 & Matrix metalloproteinase family & $\begin{array}{l}\text { Positively correlating with and as a regulatory target of TNFAIP8, degrading } \\
\text { various proteins in extracellular matrix, breaking histological barriers of normal } \\
\text { tissue which tumor cells invade, and playing a key role in tumor metastasis }\end{array}$ & {$[26,54,60,69]$} \\
\hline Integrin & Cell surface transmembrane receptor & $\begin{array}{l}\text { TNFAIP8 activating the integrin signaling, mediating cell-cell or cell-extracellular } \\
\text { matrix adhesion through ligand binding, and promoting the metastasis of tumor } \\
\text { cells }\end{array}$ & [26] \\
\hline Karyopherin $\alpha 2$ & Nucleocytoplasmic transport protein & $\begin{array}{l}\text { Binding with TNFAIP8 and promoting the transportation of TNFAIP8 into } \\
\text { nucleus }\end{array}$ & [26] \\
\hline LATS1, YAP & Hipposignaling pathway protein & $\begin{array}{l}\text { TNFAIP8 inhibiting the phosphorylation of LATS1 and YAP, leading to nuclear } \\
\text { accumulation of YAP, preventing cell contact inhibition, and promoting tissue } \\
\text { regeneration and neoplasia }\end{array}$ & [40] \\
\hline EGFR, VEGFR & Growth factor receptor & $\begin{array}{l}\text { Positively correlating with TNFAIP8, initiating the expression of relative genes, } \\
\text { and promoting cell mitosis as well as proliferation }\end{array}$ & {$[26,41,60]$} \\
\hline $\begin{array}{l}\text { Cyclin D1, } \\
\text { phospho-Rb }\end{array}$ & Cell cycle protein & $\begin{array}{l}\text { Positively correlating with TNFAIP8, facilitating cell circle progression from G1 } \\
\text { to S phase, and enhancing cell proliferation }\end{array}$ & {$[40,42]$} \\
\hline $\begin{array}{l}\operatorname{miR}-9, \text { miR-99a, } \\
\text { miR-22 }\end{array}$ & MicroRNA & $\begin{array}{l}\text { Binding to TNFAIP8 mRNA, blocking its translation, and reducing the } \\
\text { production of TNFAIP8 }\end{array}$ & {$[39,55,58]$} \\
\hline p53 & Anti-oncogene & $\begin{array}{l}\text { Mutations of p53 gene/protein activating the expression of TNFAIP8, repressing } \\
\text { apoptosis in precancer cells, and promoting oncogenesis }\end{array}$ & {$[62,63]$} \\
\hline
\end{tabular}




\section{TNFAIP8 and inflammatory/infectious diseases}

\section{Bacterial infection}

Compared to C57BL/6J, A/J mouse are more susceptible to Staphylococcus infections, but its potential mechanism is uncertain. It was reported that TNFAIP8 gene located at mouse chromosome 18 had different expression profile between C57BL/6J and $\mathrm{A} / \mathrm{J}$ mouse which was associated with functional changes of their macrophages. Silencing TNFAIP8 by siRNA, RAW264.7 macrophages showed a significant decrease in IL-1 $\beta$ secretion while an increase level of granulocyte-macrophage colony stimulating factor (GM-CSF) when challenged by Staphylococcus aureus. It was consistent with the peritoneal macrophage changes in mice of chromosome 18 substitution (C57BL/6J mice whose chromosome 18 is substituted for that of $\mathrm{A} / \mathrm{J}$ mice). These data implied that TNFAIP8 gene might be involved in the susceptibility of A/J mice to Staphylococcus aureus infection [66].

In mice infected by Listeria monocytogenes, TNFAIP8 knockdown reduced the liver and spleen bacterial loads, enhanced hepatocyte apoptosis, and inhibited the activation of Ras-related C3 botulinum toxin substrate 1 (RAC1). The decreased bacterial invasion and increased TNF-a induced cell apoptosis cooperatively protected the TNFAIP8-knockout mice from lethal Listeriosis. Thus, murine TNFAIP8 possibly regulates the pathogenesis of infection of Listeria monocytogenes through RAC1-GTP signaling pathway [67].

\section{Inflammatory bowel diseases}

In TNFAIP8-deficient mice, they were more sensitive to DSS-induced colitis than wild-type animals, manifested as increased body weight loss, higher level of leukocyte infiltration, bacterial invasion and inflammatory mediator release in colon, but less survived animals. TNFAIP8 deficiency resulted in obvious inhibition of murine intestinal epithelial cell proliferation and malfunction of cell renovation, which indicated that TNFAIP8 might play a protective role in colitis of mice [68].

\section{Autoinflammation}

It was found that TNF- $\alpha$ regulated TNFAIP8 expression via alteration of NF-KB nuclear translocation in human rheumatoid arthritis synovial fibroblasts (RASFs). Inhibition of TNFAIP8 using lentivirus could repress the synthesis of MMP-1 in RASFs. These changes then influenced RASFs apoptosis, migration and multiplication [69].

\section{TNFAIP8 and vascular abnormalities}

Horrevoets et al. conducted a gene analysis in human umbilical vein endothelial cells early in 1999, and confirmed several genes positively responsive to TNF-a in vitro and up-regulated in atherosclerotic lesions, which functioned in the process of leukocyte trafficking, vesicular transport, cell cycle control, apoptosis, and cellular protection against oxidative stress. TNFAIP8, a formerly unidentified gene, was among these genes and activated in atherosclerosis, nevertheless, the potential function of this newly found gene remained to be clarified in the development of vascular abnormalities [70].

Diabetes nephropathy is a diabetic vascular complication of the highest severity characterized by hyaline degeneration and proliferative atherosclerosis of glomerular arteries. It was reported that streptozotocin (STZ) induced diabetic rats to over-express TNFAIP8 in their glomeruli, and this phenomenon was also seen in renal biopsies of diabetic patients. In vitro, high glucose environment up-regulated TNFAIP8 expression and NADPH oxidase activity in mesangial cells, which was correlated with cell proliferation. These data documented that rodent TNAFIP8 appears to be a critical factor in the pathogenesis of diabetic renal injury [71].

\section{Conclusions and perspectives}

It has been 20 years since the structure of TNFAIP8 gene, transcript and protein were thoroughly described. Functions of TNFAIP8, such as anti-apoptotic effects, oncogenesis and promoting tumor development, invasion and metastasis, have been supported with substantial evidence from the published researches, and it is considered as a vital factor participating in the process of cell survive and death. However, there are still limits in TNFAIP8 research as its pathophysiological function is not fully illuminated. Most of the existing studies, focusing on malignant diseases, are merely correlation analysis, and do not mention any further regulatory mechanisms. Few data shed lights on TNFAIP8 in immune responses, but some of the conclusions are even contradictory. For example, TNFAIP8 mRNA expression was down-regulated in cancer (NSCLC) infiltrating $\mathrm{CD}^{+}{ }^{+} \mathrm{CD} 8{ }^{+} \mathrm{T}$ cells [35], whereas others observed an increasing trend of TNFAIP8 mRNA level in tumor (papillary thyroid carcinoma) infiltrating $\mathrm{CD}^{+} \mathrm{CD}^{+} \mathrm{T}$ cells [45]. Both articles were published in 2014 but neither gave any reasonable explanations about this discrepancy. A recent published study using thermal injury mice model only performed a preliminary experiment underlying 
functions of TNFAIP8 in peripheral $\mathrm{CD}^{+} \mathrm{T}$ cells rather than any other types of immune cells [22]. There are barely any relative researches in areas of sepsis and multiple organ dysfunction syndrome which need to be exploited in future.

It is indeed inspiring that some promising progress has been achieved in applications of TNFAIP8. Several studies revealed that TNFAIP8 was associated with treatment resistance of chemotherapy, which might be based on the interactions between TNFAIP8 and p53, thus cancer therapy would be improved through regulations targeting TNFAIP8[55, 57]. Meanwhile, miRNA studies proved the connections between its anti-tumor effect and TNFAIP8 expression, providing new insights into gene therapy of carcinomas $[39,55,58]$. In conclusion, there are still many blank fields in TNFAIP8 research which need to be deeply investigated so that biological and pathophysiological effects of TNFAIP8 and its clinical significance can be more profoundly comprehended in the new era.

\section{Acknowledgments}

This study was supported, in part, by grants from the National Natural Science Foundation (Nos. 81730057, 81372054, 81401592), the Beijing Nova Program (No. Z171100001117113), and the National Key Research and Development Program of China (No. 2017YFC1103302).

\section{Competing Interests}

The authors have declared that no competing interest exists.

\section{References}

1. Lee D, Kim MS, Park J, Jhon GJ, Son JH, Shin DH. A preliminary X-ray study of murine Tnfaip8/Oxi-a. Int J Mol Sci. 2014; 15: 4523-30.

2. Lou Y, Liu S. The TIPE (TNFAIP8) family in inflammation, immunity, and cancer. Mol Immunol. 2011; 49: 4-7.

3. Luan YY, Yao YM, Sheng ZY. The tumor necrosis factor-alpha-induced protein 8 family in immune homeostasis and inflammatory cancer diseases. J Biol Regul Homeost Agents. 2013; 27: 611-9.

4. Zhang X, Wang J, Fan C, Li H, Sun H, Gong S, et al. Crystal structure of TIPE2 provides insights into immune homeostasis. Nat Struct Mol Biol. 2009; 16: 89-90.

5. Wang K, Ren Y, Liu Y, Zhang J, He JJ. Tumor necrosis factor (TNF)-a-induced protein 8-like-2 (TIPE2) inhibits proliferation and tumorigenesis in breast cancer cells. Oncol Res. 2017; 25: 55-63.

6. Liu ZJ, Liu HL, Zhou HC, Wang GC. TIPE2 inhibits hypoxia-induced Wnt/ $\beta$-catenin pathway activation and EMT in glioma cells. Oncol Res. 2016; 24: 255-61.

7. Shen $\mathrm{P}$, Zhang $\mathrm{H}, \mathrm{Su} \mathrm{Z}$, Wang $\mathrm{S}, \mathrm{Xu} \mathrm{H}$. In silico analysis of tumor necrosis factor a-induced protein 8-like-1 (TIPE1) protein. PLoS One. 2015; 10 : e0134114.

8. Zhang $\mathrm{H}$, Zhu T, Liu W, Qu X, Chen $\mathrm{Y}$, Ren $\mathrm{P}$, et al. TIPE2 acts as a negative regulator linking NOD2 and inflammatory responses in myocardial ischemia/reperfusion injury. J Mol Med (Berl). 2015; 93: 1033-43.

9. Cui J, Hao C, Zhang W, Shao J, Zhang N, Zhang G, et al. Identical expression profiling of human and murine TIPE3 protein reveals links to its functions. J Histochem Cytochem. 2015; 63: 206-16.

10. Zhang Z, Liang X, Gao L, Ma H, Liu X, Pan Y, et al. TIPE1 induces apoptosis by negatively regulating Rac1 activation in hepatocellular carcinoma cells. Oncogene. 2015; 34: 2566-74.

11. Goldsmith JR, Chen YH. Regulation of inflammation and tumorigenesis by the TIPE family of phospholipid transfer proteins. Cell Mol Immunol. 2017; 14 $482-7$.
12. Cui J, Zhang G, Hao C, Wang $Y$, Lou $Y$, Zhang W, et al. The expression of TIPE1 in murine tissues and human cell lines. Mol Immunol. 2011; 48: 1548-55.

13. Sun H, Gong S, Carmody RJ, Hilliard A, Li L, Sun J, et al. TIPE2, a negative regulator of innate and adaptive immunity that maintains immune homeostasis. Cell. 2008; 133: 415-26.

14. Garzón I, Pérez-Köhler B, Garrido-Gómez J, Carriel V, Nieto-Aguilar R, Martín-Piedra MA, et al. Evaluation of the cell viability of human Wharton's jelly stem cells for use in cell therapy. Tissue Eng Part C Methods. 2012; 18: 408-19.

15. Patel S, Wang FH, Whiteside TL, Kasid U. Identification of seven differentially displayed transcripts in human primary and matched metastatic head and neck squamous cell carcinoma cell lines: implications in metastasis and/or radiation response. Oral Oncol. 1997; 33: 197-203.

16. Sullivan $\mathrm{C}$, Lage $\mathrm{CR}$, Yoder JA, Postlethwait JH, Kim $\mathrm{CH}$. Evolutionary divergence of the vertebrate TNFAIP8 gene family: applying the spotted gar orthology bridge to understand ohnolog loss in teleosts. PLoS One. 2017; 12: e0179517.

17. Shao $\mathrm{Y}$, Chen $\mathrm{H}$, Lv M, Li C, Zhang W, Li Y, et al. A novel TNFAIP8 gene mediates L-arginine metabolism in Apostichopusjaponicus. Fish Shellfish Immunol. 2017; 69: 26-34.

18. Li $Y$, Jing $C$, Chen $Y$, Wang J, Zhou M, Liu X, et al. Expression of tumor necrosis factor a-induced protein 8 is upregulated in human gastric cancer and regulates cell proliferation, invasion and migration. Mol Med Rep. 2015; 12: 2636-42

19. Zhang Y, Wang MY, He J, Wang JC, Yang YJ, Jin L, et al. Tumor necrosis factor- $\alpha$ induced protein 8 polymorphism and risk of non-Hodgkin's lymphoma in a Chinese population: a case-control study. PLoS One. 2012; 7: e37846.

20. Kumar D, Whiteside TL, Kasid U. Identification of a novel tumor necrosis factor-alpha-inducible gene, SCC-S2, containing the consensus sequence of a death effector domain of Fas-associated death domain-like interleukin1beta-converting enzyme-inhibitory protein. J Biol Chem. 2000; 275: 2973-8.

21. Woodward MJ, de Boer J, Heidorn S, Hubank M, Kioussis D, Williams O, et al. Tnfaip8 is an essential gene for the regulation of glucocorticoid-mediated apoptosis of thymocytes. Cell Death Differ. 2010; 17: 316-23.

22. Xin $\mathrm{Y}$, Wan DH, Wang X, Gao XJ, Xu XJ, Ju XL, et al. Effect of tumor necrosis factor-induced protein 8 on T-cell-mediated immunity in mice after thermal njury. J Biol Regul Homeost Agents. 2016; 30: 777-84.

23. Chu P, Pardo J, Zhao H, Li CC, Pali E, Shen MM, et al. Systematic identification of regulatory proteins critical for T-cell activation. J Biol. 2003; 2: 21.

24. Day TF, Mewani RR, Starr J, Li X, Chakravarty D, Ressom H, et al. Transcriptome and proteome analyses of TNFAIP8 knockdown cancer cells reveal new insights into molecular determinants of cell survival and tumor progression. Methods Mol Biol. 2017; 1513: 83-100.

25. Salihu HM, Das R, Morton L, Huang H, Paothong A, Wilson RE, et al. Racial differences in DNA-methylation of CpG sites within preterm-promoting genes and gene variants. Matern Child Health J. 2016; 20: 1680-7.

26. Zhang C, Kallakury BV, Ross JS, Mewani RR, Sheehan CE, Sakabe I, et al. The significance of TNFAIP8 in prostate cancer response to radiation and docetaxel and disease recurrence. Int J Cancer. 2013; 133: 31-42.

27. Takahashi Y, Tsuruta S, Honda A, Fujiwara Y, Satoh M, Yasutake A. Effect of dental amalgam on gene expression profiles in rat cerebrum, cerebellum, liver and kidney. J Toxicol Sci. 2012; 37: 663-6.

28. You Z, Ouyang H, Lopatin D, Polver PJ, Wang CY. Nuclear factor-kappa B-inducible death effector domain-containing protein suppresses tumor necrosis factor-mediated apoptosis by inhibiting caspase- 8 activity. J Biol Chem. 2001; 276: 26398-404.

29. Zhang LJ, Liu X, Gafken PR, Kioussi C, Leid M. A chicken ovalbumin upstream promoter transcription factor I (COUP-TFI) complex represses expression of the gene encoding tumor necrosis factor alpha-induced protein 8 (TNFAIP8). J Biol Chem. 2009; 284: 6156-68.

30. Laliberté B, Wilson AM, Nafisi H, Mao H, Zhou YY, Daigle M, et al. TNFAIP8: a new effector for Galpha(i) coupling to reduce cell death and induce cell transformation. J Cell Physiol. 2010; 225: 865-74.

31. Chittaranjan S, Xu J, Kuzyk M, Dullat HK, Wilton J, DeVorkin L, et al. The Drosophila TIPE family member Sigmar interacts with the Ste20-like kinase Misshapen and modulates JNK signaling, cytoskeletal remodeling and autophagy. Biol Open. 2015; 4: 672-84.

32. Choi KC, Kim SH, Ha JY, Kim ST, Son JH. A novel mTOR activating protein protects dopamine neurons against oxidative stress by repressing autophagy related cell death. J Neurochem. 2010; 112: 366-76.

33. Kim JS, Park J, Kim MS, Ha JY, Jang YW, Shin DH, et al. The Tnfaip8-PE complex is a novel upstream effector in the anti-autophagic action of insulin. Sci Rep. 2017; 7: 6248.

34. Dong QZ, Zhao $Y$, Liu $Y$, Wang $Y$, Zhang PX, Jiang GY, et al. Overexpression of SCC-S2 correlates with lymph node metastasis and poor prognosis in patients with non-small-cell lung cancer. Cancer Sci. 2010; 101: 1562-9.

35. Wang $L$, Song $Y$, Men $X$. Variance of TNFAIP8 expression between tumor tissues and tumor-infiltrating $\mathrm{CD}^{+}$and $\mathrm{CD} 8^{+} \mathrm{T}$ cells in non-small cell lung cancer. Tumour Biol. 2014; 35: 2319-25.

36. Chen L, Yang X, Yang X, Fan K, Xiao P, Zhang I, et al. Association between the expression levels of tumor necrosis factor-a-induced protein 8 and the prognosis of patients with gastric adenocarcinoma. Exp Ther Med. 2016; 12: $238-44$. 
37. Hu R, Qiu X, Hong S, Meng L, Hong X, Qiu J, et al. Clinical significance of TIPE expression in gastric carcinoma. Onco Targets Ther. 2016; 9: 4473-81.

38. Yang M, Zhao Q, Wang X, Liu T, Yao G, Lou C, et al. TNFAIP8 overexpression is associated with lymph node metastasis and poor prognosis in intestinal-type gastric adenocarcinoma. Histopathology. 2014; 65: 517-26.

39. Gao HY, Huo FC, Wang HY, Pei DS. MicroRNA-9 inhibits the gastric cancer cell proliferation by targeting TNFAIP8. Cell Prolif. 2017; 50: doi:10.1111/cpr.12331.

40. Dong Q, Fu L, Zhao Y, Xie C, Li Q, Wang E. TNFAIP8 interacts with LATS1 and promotes aggressiveness through regulation of Hippo pathway in hepatocellular carcinoma. Oncotarget. 2017; 8: 15689-703.

41. Liu K, Qin CK, Wang ZY, Liu SX, Cui XP, Zhang DY. Expression of tumor necrosis factor-alpha-induced protein 8 in pancreas tissues and its correlation with epithelial growth factor receptor levels. Asian Pac J Cancer Prev. 2012; 13: 847-50.

42. Miao Z, Zhao T, Wang Z, Xu Y, Song Y, Wu J, et al. SCC-S2 is overexpressed in colon cancers and regulates cell proliferation. Tumour Biol. 2012; 33: 2099-106.

43. Hadisaputri YE, Miyazaki T, Suzuki S, Yokobori T, Kobayashi T, Tanaka N, et al. TNFAIP8 overexpression: clinical relevance to esophageal squamous cell carcinoma. Ann Surg Oncol. 2012; 19 Suppl 3: S589-96.

44. Sun Z, Liu X, Song JH, Cheng Y, Liu Y, Jia Y, et al. TNFAIP8 overexpression: a potential predictor of lymphatic metastatic recurrence in $\mathrm{pN} 0$ esophageal squamous cell carcinoma after Ivor Lewis esophagectomy. Tumour Biol. 2016; 37: 10923-34

45. Duan D, Zhu YQ, Guan LL, Wang J. Upregulation of SCC-S2 in immune cells and tumor tissues of papillary thyroid carcinoma. Tumour Biol. 2014; 35: 4331-7.

46. Zhang $\mathrm{Y}$, Chen MB, Zhou XY, Hong XN. Lymphotoxin alpha (LTA) polymorphism is associated with prognosis of non-Hodgkin's lymphoma in a Chinese population. PLoS One. 2013; 8: e66411.

47. Deeb SJ, Tyanova S, Hummel M, Schmidt-Supprian M, Cox J, Mann M. Machine learning-based classification of diffuse large B-cell lymphoma patients by their protein expression profiles. Mol Cell Proteomics. 2015; 14: 2947-60.

48. Eisele L, Klein-Hitpass L, Chatzimanolis N, Opalka B, Boes T, Seeber S, et al. Differential expression of drug-resistance-related genes between sensitive and resistant blasts in acute myeloid leukemia. Acta Haematol. 2007; 117: 8-15.

49. Wang MC, Liu SX, Liu PB. Gene expression profile of multiple myeloma cell line treated by realgar. J Exp Clin Cancer Res. 2006; 25: 243-9.

50. Wang Y, Hayakawa J, Long F, Yu Q, Cho AH, Rondeau G, et al. "Promoter array" studies identify cohorts of genes directly regulated by methylation, copy number change, or transcription factor binding in human cancer cells. Ann N Y Acad Sci. 2005; 1058: 162-85

51. Wang Y, Yu Q, Cho AH, Rondeau G, Welsh J, Adamson E, et al. Survey of differentially methylated promoters in prostate cancer cell lines. Neoplasia. 2005; 7: 748-60.

52. Romanuik TL, Ueda T, Le N, Haile S, Yong TM, Thomson T, et al. Novel biomarkers for prostate cancer including noncoding transcripts. Am J Pathol. 2009; 175: 2264-76.

53. Cheng Y, Yu P, Duan X, Liu C, Xu S, Chen Y, et al. Genome-wide analysis of androgen receptor binding sites in prostate cancer cells. Exp Ther Med. 2015; 9: 2319-24

54. Liu T, Gao H, Yang M, Zhao T, Liu Y, Lou G. Correlation of TNFAIP8 overexpression with the proliferation, metastasis, and disease-free survival in endometrial cancer. Tumour Biol. 2014; 35: 5805-14.

55. Shi TY, Cheng X, Yu KD, Sun MH, Shao ZM, Wang MY, et al. Functional variants in TNFAIP8 associated with cervical cancer susceptibility and clinical outcomes. Carcinogenesis. 2013; 34: 770-8.

56. Liu T, Gao H, Chen X, Lou G, Gu L, Yang M, et al. TNFAIP8 as a predictor of metastasis and a novel prognostic biomarker in patients with epithelial ovarian cancer. Br J Cancer. 2013; 109: 1685-92.

57. Liu T, Xia B, Lu Y, Xu Y, Lou G. TNFAIP8 overexpression is associated with platinum resistance in epithelial ovarian cancers with optimal cytoreduction. Hum Pathol. 2014; 45: 1251-7.

58. Xing B, Ren C. Tumor-suppressive miR-99a inhibits cell proliferation via targeting of TNFAIP8 in osteosarcoma cells. Am J Transl Res. 2016; 8: 1082-90.

59. Kumar D, Gokhale P, Broustas C, Chakravarty D, Ahmad I, Kasid U. Expression of SCC-S2, an antiapoptotic molecule, correlates with enhanced proliferation and tumorigenicity of MDA-MB 435 cells. Oncogene. 2004; 23: 612-6.

60. Zhang C, Chakravarty D, Sakabe I, Mewani RR, Boudreau HE, Kumar D, et al. Role of SCC-S2 in experimental metastasis and modulation of VEGFR-2, MMP-1, and MMP-9 expression. Mol Ther. 2006; 13: 947-55.

61. Xiao M, Xu Q, Lou C, Qin Y, Ning X, Liu T, et al. Overexpression of TNFAIP8 is associated with tumor aggressiveness and poor prognosis in patients with invasive ductal breast carcinoma. Hum Pathol. 2017; 62: 40-9.

62. Monteith JA, Mellert H, Sammons MA, Kuswanto LA, Sykes SM, Resnick-Silverman L, et al. A rare DNA contact mutation in cancer confers p53 gain-of-function and tumor cell survival via TNFAIP8 induction. Mol Oncol. 2016; 10: 1207-20.

63. Lowe JM, Nguyen TA, Grimm SA, Gabor KA, Peddada SD, Li L, et al. The novel p53 target TNFAIP8 variant 2 is increased in cancer and offsets p53-dependent tumor suppression. Cell Death Differ. 2017; 24: 181-91.
64. Del PHL, Martins AS, Milsted A, Souza-Fagundes EM, Braz GF, Hissa B, et al. Canine distemper virus induces apoptosis in cervical tumor derived cell lines. Virol J. 2011; 8: 334.

65. Garcia JA, Ferreira HL, Vieira FV, Gameiro R, Andrade AL, Eugênio FR, et al. Tumour necrosis factor-alpha-induced protein 8 (TNFAIP8) expression associated with cell survival and death in cancer cell lines infected with canine distemper virus. Vet Comp Oncol. 2017; 15: 336-44.

66. Ahn SH, Deshmukh H, Johnson N, Cowell LG, Rude TH, Scott WK, et al. Two genes on $\mathrm{A} / \mathrm{J}$ chromosome 18 are associated with susceptibility to Staphylococcus aureus infection by combined microarray and QTL analyses. PLoS Pathog. 2010; 6: e1001088.

67. Porturas TP, Sun H, Buchlis G, Lou Y, Liang X, Cathopoulis T, et al. Crucial roles of TNFAIP8 protein in regulating apoptosis and Listeria infection. J Immunol. 2015; 194: 5743-50.

68. Sun H, Lou Y, Porturas T, Morrissey S, Luo G, Qi J, et al. Exacerbated experimental colitis in TNFAIP8-deficient mice. J Immunol. 2015; 194: 5736-42.

69. Zhang HG, Hyde K, Page GP, Brand JP, Zhou J, Yu S, et al. Novel tumor necrosis factor alpha-regulated genes in rheumatoid arthritis. Arthritis Rheum. 2004; 50: 420-31.

70. Horrevoets AJ, Fontijn RD, van Zonneveld AJ, de Vries CJ, ten CJW, Pannekoek $\mathrm{H}$. Vascular endothelial genes that are responsive to tumor necrosis factor-alpha in vitro are expressed in atherosclerotic lesions, including inhibitor of apoptosis protein-1, stannin, and two novel genes. Blood. 1999; 93: 3418-31.

71. Zhang S, Zhang Y, Wei X, Zhen J, Wang Z, Li M, et al. Expression and regulation of a novel identified TNFAIP8 family is associated with diabetic nephropathy. Biochim Biophys Acta. 2010; 1802: 1078-86. 